\title{
A METHOD FOR PREDICTING FAILURE LOAD OF MASONRY WALL PANEL BASED ON STRUCTURAL STRESS STATE
}

\author{
Yanxia Huang $^{1,2}$ - Qunyi Huang ${ }^{3 *}-$ Liang Cui $^{4}-$ Keyue Zhang ${ }^{3}-$ Ming Zhang $^{3}$ \\ ${ }^{1}$ School of Civil and Architectural Engineering, Anyang institute of Technology, Anyang, Henan, CN \\ ${ }^{2}$ School of Mechanics and Engineering, Southwest Jiaotong University, Chengdu, Sichuan, CN \\ ${ }^{3}$ School of Civil Engineering, Southwest Jiaotong University, Chengdu, CN \\ ${ }^{4}$ Department of Civil Environmental Engineering, University of Surrey, Guildford, Surrey, UK
}

\begin{tabular}{l} 
ARTICLE INFO \\
\hline Article history: \\
Received: 26. 8. 2017. \\
Received in revised form: 19. 1. 2018. \\
Accepted: 22. 1. 2018. \\
\hline Keywords: \\
Masonry wall panel \\
Structural stress state \\
Failure load \\
ST method \\
GSED-based CA method \\
\hline DOI: http://doi.org/10.30765/er.40.2.01
\end{tabular}

\section{Introduction}

Masonry is vastly used in the construction of structural and non-structural walls. To date, commonly used methods to investigate the behavior of masonry wall panels are experimental method [1,2], the Yield Line Theory (YLT) method [3] and the Finite Element Analysis (FEA) method [4-9]. However, it was pointed out that there was no rational justification for the use of a yield line theory based on ductile behavior for a brittle

\begin{abstract}
:
This paper proposed a method for predicting failure loads of masonry wall panels subject to uniformly distributed lateral loading based on a concept of structural stress state. Firstly, the characteristics of the structural stress state of masonry wall panels subjected to uniform distributed lateral loading were investigated through experimental results. Then, a new parameter was proposed to characterize the structural stress state. Next, the relation of the failure loads between a specified base wall panels and other wall panel was established using the proposed parameter. In this way, a method (called a ST method) based on a structural stress state parameter to predict the failure load of masonry wall panel from the base wall panel was established. The following case studies validated the ST method by comparing the predicted failure load with the experimental results, as well as those predicted from the existing yield line theory (YLT), the FEA method and the GSED-based cellular automata (CA) method. The ST method provided an innovative way of structural analysis on the basis of structural stress state.
\end{abstract}

material like masonry [10], while for the experimental method, it is expensive and time consuming. With the advent of high power computers, the FEA methods have become one economic way in studying masonry structures. However, the accuracy of the FEA methods largely depends on the time step definition of proper material properties and the discretization of the continuum. As mentioned by Lawrence [11], there were two pivotal factors affecting the behavior of masonry wall panels, the boundary conditions and the variation in masonry properties. These two

\footnotetext{
* Corresponding author.

E-mail address: hqy1986@swjtu.edu.cn
} 
factors result in large difficulties for researchers in simulating the variation of the masonry using the FEA method, especially in relating with the variation.

To address the issue, Zhou et al [12] introduced an artificial intelligence technology into the analysis of laterally loaded masonry wall panels. He proposed a Cellular Automata (CA) method to predict the failure patterns of the new wall panels, by directly using the experimental failure pattern of a masonry wall panel. Then, Zhang et al [13] and Huang et al $[14,15]$ further verified the CA method by extending and improving its internal functions. These studies indicated that the CA method could be used to predict the failure pattern of masonry wall panel and obtain satisfied results, moreover, the variation of the new masonry wall panels could be displayed by introducing the variation on the base wall panel. However, this CA method is not able to predict the failure loads of that wall panels. A major progress of the CA method was that Huang et al [16] proposed a concept of generalized strain energy density (GSED) and established a GSED-based CA method, which extended the CA method to predict the failure loads of laterally loaded masonry wall panels. However, the GSED-based CA method was relatively complex in the modeling process of masonry wall panels. Besides, the CA model of the masonry wall panel was both numerical and empirical, unlike the mechanical models in the FEA method. Therefore, this paper tried to extract the strain energy density from the FEA model and use the normalized strain energy density (NSED) to express the structural stress state (ST). Furthermore, a NSED based ST method was proposed to predict the failure loads of laterally loaded masonry wall panels.

\section{Structural stress state mode}

Structural stress state mode (ST mode) means the distribution profile of SED values within the wall panel under a given loading condition. To illustrate the features of the structural stress state mode, a masonry wall panel SB05 tested by Chong [5] is considered here. The Panel SB05 was subjected to lateral evenly distributed load, with dimension of $5600 \mathrm{~mm} \times 2475 \mathrm{~mm}$ in plane. The bottom edge of the panel was fixed and the two vertical edges were simply supported. 36 measuring points were evenly arranged at the crossings of the dashed lines shown in Fig 1. In the experiment, the displacements of the
36 measuring points with loading increments were recorded.

To represent the stress state of each zone without magnitude effect, the square of displacement (SD) of each measuring point is normalized by the maximum SD value among all measuring points. The distribution of the normalized SD values is defined as the ST mode whose contour profiles under different loading increments are shown in Fig. 2.

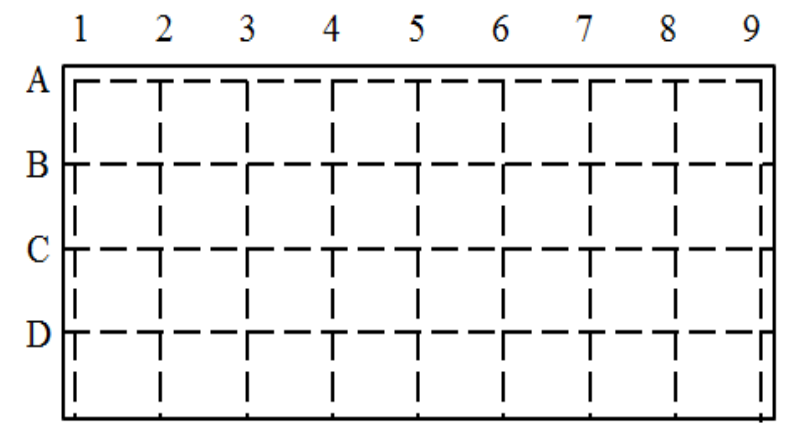

Figure 1. The measuring point locations of the Panel SB05

It can be seen from the Fig. 2 that the ST modes of Panel SB05 can be divided into three different stages: preliminary stage, normal stress stage and failure stage. For the preliminary stage, the external loading is smaller than $0.8 \mathrm{kN}$, the ST mode is changing because all the zones on the wall panel need a period to reach a full stress state. For the normal stress stage, the external loading is greater than $0.8 \mathrm{kN}$, the zones on the Panel SB05 are in the normal and full stressing state. During this stage (from $0.8 \mathrm{kN}$ to $2.6 \mathrm{kN}$ ), the ST mode basically remains unchanged with the load increase. For the failure stage after $2.7 \mathrm{kN}$, the ST mode of the panel changes qualitatively until the panel collapse. Therefore, the ST mode of the Panel SB05 basically maintains the same during its normal working stage; once the ST mode leaps to the variable one, the wall panel is in a failure state so that the corresponding load is called the failure load. From Fig. 2, two basic characteristics of the ST mode can be summarized: (1) with a load increase, the ST mode remains the same. In other words, within the failure load, the ST mode of a structure is related to structural configuration, material property and the load type, but independent on the magnitude of the load. (2) The ST mode can be used to reflect the working behavior of the structure. Once a characteristic parameter is obtained from the ST 
mode, it can be applied to predict the failure load of the structure or to demonstrate the characteristics of structural working behavior.

To represent the characteristics of ST mode, a suitable parameter should be defined. Traditionally, a constitutive relation between stress and strain is applied to reflect the property of a material and to simulate the behavior of a structure. However, strain and stress with their orientations are inapplicable to characterize the ST mode. Although SED values connect both strain and stress and are algebraic quantities without a limitation of directionality, they are applied to represent the ST mode. Furthermore,
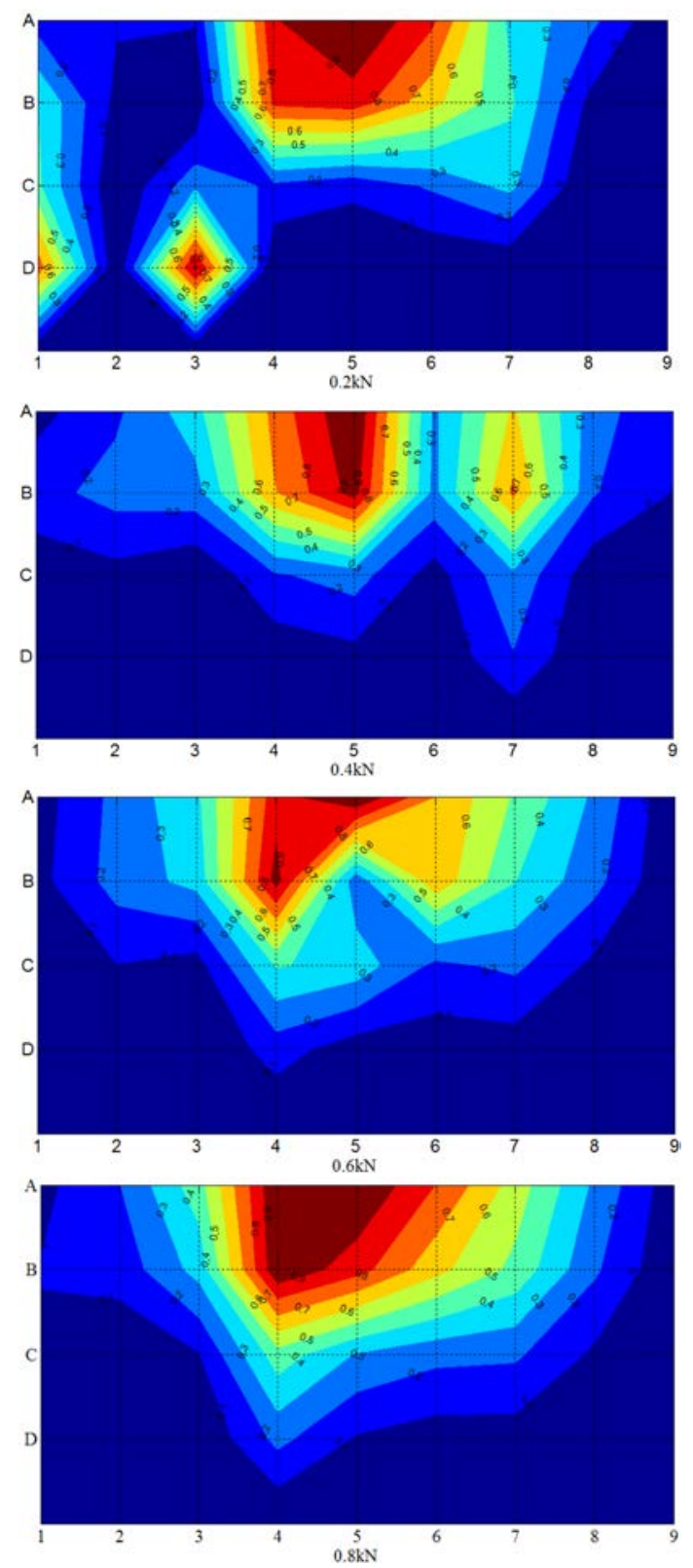

the sum of NSED values is taken as the characteristic parameter for the ST mode. In addition, if the experimental data are displacements of all the measuring points, the sum of normalized square displacements (NSD) can be used as the characteristic parameter to describe the characteristics of the ST mode. Figure 3 is the curve of the sum of NSD versus load for a representative test, which shows the three stages as observed in Fig. 2. Obviously, the sum of NSD also embodies the two basic characteristics as stated previously. Hence, the NSD/NSED sum can be used as the ST parameters.
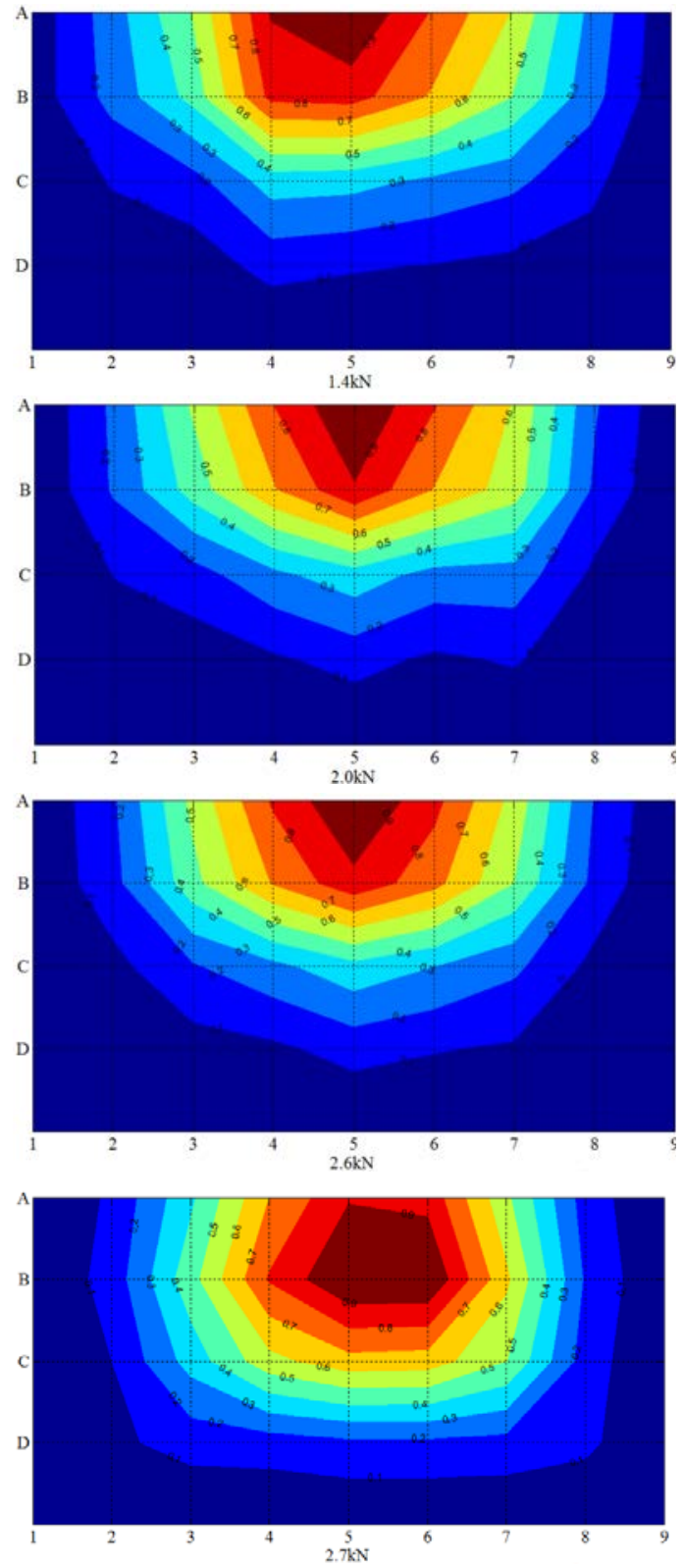

Figure 2. The structural stress state modes of the Panel SB05 under different loading increments 


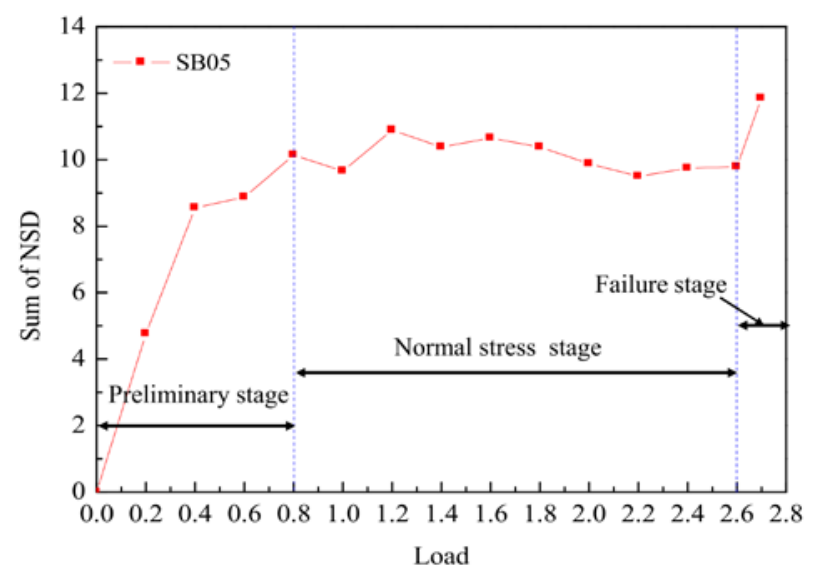

Figure 3. Curve of the sum of NSD versus load for SB05

Generally, the SED can be expressed by Young's modules $E$ and the strain $\varepsilon$, as shown in Eq. (1)

$$
w=\frac{1}{2} E \varepsilon^{2}
$$

The normalized SED value (NSED) is expressed by Eq. (2).

$$
D_{i, j}=\frac{w_{i, j}}{\max (w)} i=1,2 \cdots M, j=1,2 \cdots N
$$

Where, $w_{i, j}$ is the SED value of zone $(i, j)$ under the unit load; $\max (w)$ means the maximum SED value among all cells; $D_{i, j}$ is the NSED value of zone ( $i$, $j) ; M, N$ are the row and column of wall panel, respectively. There are three points to be addressed for Eqs. (1) and (2): (1) Young's modules and Poisson's ratio are artificially assumed because they are not necessary to be the practical or actual values in the ST mode; thus, the FEA modelling is simplified and computational costs are reduced. (2) The SED values are extracted from the linear or elastic response of masonry wall panels. (3) The NSED values are dimensionless quantities and independent on the real external load, but show the distribution of NSED (or the relative value) of each cell on the wall panel. Hence, the ST parameter (sum of NSED values) reflects the working characteristic of the entire structure, which lays the foundation of the ST method for predicting the failure loads of wall panels.
3 Method for predicting failure load of masonry wall panels based on the ST mode

\subsection{The deduction of the ST based method}

The ST parameter $c$ can be calculated by Eq. (3):

$$
C=\sum_{i=1}^{M} \sum_{j=1}^{N} D_{i, j}
$$

where, $D_{i, j}$ is the NSED value (or normalized square displacement) of cell $(i, j) ; M, N$ are the row and column numbers of the divided zones on a wall panel, respectively. The ST base parameters and new wall panels, as well as the failure load of the base panel, can be used to establish the failure criterion $f$ of the new wall panel based on the ST parameter $c$, as shown in Eq. (4):

$$
F_{\text {new }}=f\left(c_{\text {base }}, c_{\text {new }}, F_{\text {base }}\right)
$$

where, $c_{\text {base }}, c_{\text {new }}$ are the ST parameters of the base wall panel and the new wall panel, respectively; $F_{\text {base }}$ and $F_{\text {new }}$ are the failure loads of the base wall panel and the new wall panel, respectively; $f$ is the failure criterion. It is assumed that the base and new wall panels have same stress states at the failure stages. Hence, the relationship can be expressed by Eq. (5)

$$
c_{\text {base }} F_{\text {base }}=c_{\text {new }} F_{\text {new }}
$$

Form Eq. (5), the failure load of the new wall panel can be calculated by Eq. (6):

$$
F_{\text {new }}=F_{\text {base }} \frac{C_{\text {base }}}{C_{\text {new }}}
$$

This proposed criterion will be validated as detailed in the following sections.

\subsection{The ST method procedure}

So far, the method for predicting the failure load of masonry wall panel based on the ST concept is formed and its procedure is shown in Fig. 4. For the ST method, the first step is to calculate the SEDs of the new and base wall panels under unit uniformly distributed load using the FEA method, respectively. 
The size of each cell on the base and new wall panels should be the same. The second step is to calculate the NSEDs of all the cells on the new and base wall panels using Eq. (2), respectively. The third step is to calculate the ST parameters of the new and base wall panels using Eq. (3), respectively. The final step is to calculate the failure load of the new wall panel using Eq. (6).

\subsection{Case studies on verification of the ST method}

The boundary conditions of wall panels can be classified into two main types: (1) the top edge is free and the other three edges are constrained; (2) four edges are all constrained. Therefore, the masonry wall panels used in the following case studies mainly follow these two constraint types. To validate the ST method, for the wall panels with the first constraint type, the wall panels tested in the University of Plymouth [5] are used; while to validate the ST method for the wall panels with the second constraint type, the wall panels tested by Lawrence [11] are used. The failure loads of these tested wall panels are used to compare to the results predicted by the ST method. Moreover, the results predicted by the ST method are also compared to the results predicted by the yield line theory (YLT), finite element analysis (FEA) method, and GSEDbased CA method from the authors' previous study [16]. The comparisons adopt the following evaluating formulas, for instance, for the YLT method where, $E_{\mathrm{YLT}}$ is the relative error between the predicted failure load using the yield line theory and the tested failure load for each wall panel, and $E_{\mathrm{YLT}}^{\mathrm{ave}}$ is the corresponding average absolute error of all wall panels; $F_{\text {new }}$ is the predicted failure load of the new wall panel; $F_{\text {exp }}$ is the tested failure load of the new wall panel; $n$ is the number of the new wall panels. Similarly, the errors $E_{\mathrm{FEA}}, E_{\mathrm{GSED}}$, and $E_{\mathrm{ST}}$, together with the corresponding average absolute errors $E_{\mathrm{FEA}^{\mathrm{a}}}^{\mathrm{ave}}, E_{\mathrm{GSED}}^{\mathrm{ave}}$ and $E_{\mathrm{ST}}^{\text {ave }}$ can be obtained.

$$
\begin{gathered}
E_{\mathrm{YLT}}=\frac{F_{\text {new }}-F_{\text {exp }}}{F_{\text {exp }}} \\
E_{\mathrm{YLT}}^{\mathrm{ave}}=\frac{1}{n} \sum_{i=1}^{n}\left|E_{\mathrm{YLT}}^{i}\right|
\end{gathered}
$$

The wall panels tested have two different thicknesses, $0.215 \mathrm{~m}$ and $0.1025 \mathrm{~m}$. For the wall panels with the thickness of $0.1025 \mathrm{~m}$, Panel 1109 (3.6 $\mathrm{m} \times 4.5 \mathrm{~m}$ in plane) was selected as the base wall panel to predict the failure loads of other masonry wall panels with different dimensions. The predicted results and errors in comparison are listed in Table 1. Similarly, Table 2 lists the same items, but Wall Panel $1173(3.6 \mathrm{~m} \times 4.5 \mathrm{~m} \times 0.215 \mathrm{~m})$ is the base wall panel.

It can be seen from Tables 1 and 2 that the ST method is accurate in predicting the failure loads of masonry wall panels when compared with the tested results.

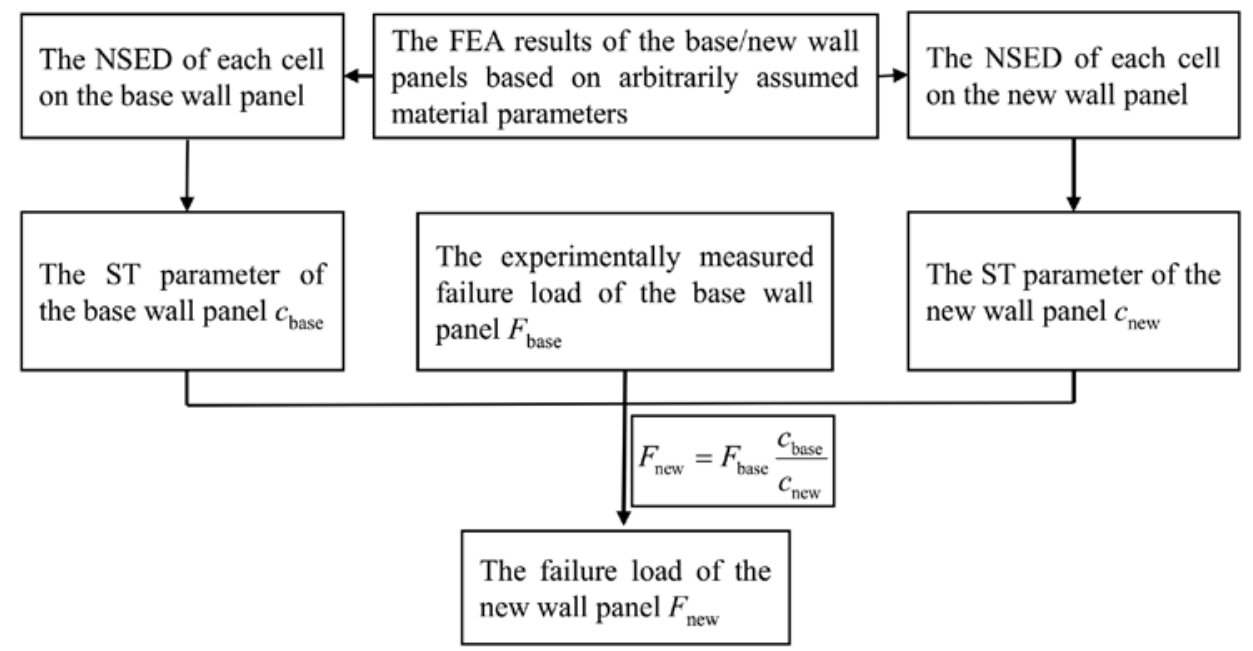

Figure 4. The ST method procedure 
Table 1. The parameters and predicted failure loads of the New Wall Panels with the thickness of 0.1025m (Base Wall Panel 1109)

\begin{tabular}{|c|c|c|c|c|c|c|c|c|c|c|}
\hline No. & $\begin{array}{c}\text { Dimension } \\
(\mathrm{m})\end{array}$ & $\begin{array}{c}F_{\text {tested }} \\
\left(\mathrm{kN} / \mathrm{m}^{2}\right)\end{array}$ & $\begin{array}{c}F_{\mathrm{YLT}} \\
\left(\mathrm{kN} / \mathrm{m}^{2}\right)\end{array}$ & $E_{\mathrm{YLT}}$ & $\begin{array}{c}F_{\mathrm{FEA}} \\
\left(\mathrm{kN} / \mathrm{m}^{2}\right)\end{array}$ & $E_{\mathrm{FEA}}$ & $\begin{array}{c}F_{\mathrm{GSED}} \\
\left(\mathrm{kN} / \mathrm{m}^{2}\right)\end{array}$ & $E_{\mathrm{GSED}}$ & $\begin{array}{c}F_{\mathrm{ST}} \\
\left(\mathrm{kN} / \mathrm{m}^{2}\right)\end{array}$ & $E_{\mathrm{ST}}$ \\
\hline 1135 & $2.6 \times 2.7$ & 6.5 & 9.87 & $51.85 \%$ & 6.85 & $5.38 \%$ & 8.20 & $26.15 \%$ & 7.87 & $21.08 \%$ \\
\hline 1095 & $3.6 \times 5.5$ & 2.9 & 2.77 & $-4.48 \%$ & 1.95 & $-32.76 \%$ & 2.86 & $-1.38 \%$ & 2.27 & $-21.72 \%$ \\
\hline 1171 & $5.2 \times 5.5$ & 2.2 & 2.41 & $9.55 \%$ & 1.67 & $-24.09 \%$ & 1.86 & $-15.45 \%$ & 2.02 & $-8.18 \%$ \\
\hline
\end{tabular}

Table 2. The parameters and predicted failure loads of New Wall Panels with the thickness of 0.215m (Base Wall Panel 1173)

\begin{tabular}{|c|c|c|c|c|c|c|c|c|c|c|}
\hline No. & $\begin{array}{l}\text { Dimension } \\
\text { (m) }\end{array}$ & $\begin{array}{c}F_{\text {tested }} \\
\left(\mathrm{kN} / \mathrm{m}^{2}\right)\end{array}$ & $\begin{array}{c}F_{\mathrm{YLT}} \\
\left(\mathrm{kN} / \mathrm{m}^{2}\right)\end{array}$ & $E_{\mathrm{YLT}}$ & $\begin{array}{c}F_{\mathrm{FEA}} \\
\left(\mathrm{kN} / \mathrm{m}^{2}\right)\end{array}$ & $E_{\mathrm{FEA}}$ & $\begin{array}{c}F_{\mathrm{GSED}} \\
\left(\mathrm{kN} / \mathrm{m}^{2}\right)\end{array}$ & $E_{\mathrm{GSED}}$ & $\begin{array}{c}F_{\mathrm{ST}} \\
\left(\mathrm{kN} / \mathrm{m}^{2}\right)\end{array}$ & $E_{\mathrm{ST}}$ \\
\hline 1172 & $2.6 \times 2.7$ & 20.9 & 31.35 & $50.00 \%$ & 23.75 & $13.64 \%$ & 20.01 & $-4.26 \%$ & 19.64 & $-6.03 \%$ \\
\hline 1169 & & 9.5 & 14.40 & $51.58 \%$ & 11.66 & $22.74 \%$ & 12.53 & $31.89 \%$ & 8.54 & \\
\hline 1244 & 4.5 & 8.0 & 12.31 & $53.88 \%$ & 9.49 & $18.63 \%$ & 6.42 & $-19.75 \%$ & 7.02 & \\
\hline 1150 & $2.6 \times$ & 10.7 & 11.05 & $3.27 \%$ & 8.83 & $-17.48 \%$ & 10.39 & $-2.90 \%$ & $6.29 / 10.6$ & $-41.21 \% /-0.5$ \\
\hline 1153 & $3.6 \times$ & 6.7 & 9.06 & $35.22 \%$ & 7.04 & $5.07 \%$ & 7.03 & $4.93 \%$ & 5.67 & $-15.37 \%$ \\
\hline 237 & $4.5 \times 5.5$ & 6.5 & 8.24 & $26.77 \%$ & 6.20 & $-4.62 \%$ & 5.30 & $-18.46 \%$ & 5.30 & $-18.46 \%$ \\
\hline \multicolumn{4}{|c|}{ Average error $E^{\text {ave }}$} & $36.79 \%$ & & $13.69 \%$ & & $13.70 \%$ & & $17.24 \% / 10.45 \%$ \\
\hline
\end{tabular}

Table 3. The parameters and predicted failure loads of new wall panels (Base Wall Panel Test 8)

\begin{tabular}{|c|c|c|c|c|c|c|}
\hline No. & $\begin{array}{c}\text { Dimensions } \\
(\mathrm{m})\end{array}$ & $\begin{array}{c}F_{\text {tested }} \\
\left(\mathrm{kN} / \mathrm{m}^{2}\right)\end{array}$ & $\begin{array}{c}F_{\mathrm{GSED}} \\
\left(\mathrm{kN} / \mathrm{m}^{2}\right)\end{array}$ & $E_{\mathrm{GSED}}$ & $\begin{array}{c}F_{\mathrm{ST}} \\
\left(\mathrm{kN} / \mathrm{m}^{2}\right)\end{array}$ & $E_{\mathrm{ST}}$ \\
\hline Test12 & $2.5 \times 2.5 \times 0.112$ & 8.6 & 10.47 & $21.74 \%$ & 7.99 & $-7.09 \%$ \\
\hline Test22 & $2.5 \times 5 \times 0.111$ & 4.7 & 4.88 & $3.83 \%$ & 4.55 & $-3.19 \%$ \\
\hline Test27 & $2.5 \times 6 \times 0.109$ & 3.1 & 3.98 & $28.39 \%$ & 3.91 & $26.13 \%$ \\
\hline Test32 & $3 \times 6 \times 0.109$ & 3.5 & 3.2 & $-8.57 \%$ & 3.2 & $-8.57 \%$ \\
\hline \multicolumn{7}{|c|}{ Average error $E^{\text {ave }}$} \\
\hline
\end{tabular}

The accuracy of the ST method is better than the yield line method. In particular, for the panels with $0.215 \mathrm{~m}$ thickness, the accuracy is $20 \%$ higher than that of the yield line theory. The accuracy of the ST method is also higher than the FEA method for the wall panels with $0.1025 \mathrm{~m}$ thickness, but about $3.55 \%$ lower for the wall panels with $0.215 \mathrm{~m}$ thickness. The accuracy of the ST method is slightly lower than the GSED based method for the wall panels with both thicknesses.

The predicted error is as high as to $-41.12 \%$ when using the Wall Panel 1173 as the base wall panel to predict the failure load of Wall Panel 1150. This is because the Wall Panel 1173 is a two-way wall panel while the Wall Panel 1150 is a one-way wall panel. It is well known that the stress state in a twoway (the ratio of length to width is smaller than 2) wall panel is quite different from that in a one-way (the ratio between the length and the width is larger than 2) wall panel. However, the size effect of the wall panel was not taken into account during the entire predicting procedure of the ST method; therefore, a size effect parameter was suggested to improve the predicted results when the base and new wall panel are different types (one-way wall panel or two-way wall panel). The size effect parameter can be calculated by Eq. (9) and the failure load of the new wall panel is calculated by Eq. (10).

$$
\xi=\frac{L_{n} / H_{n}}{L_{b} / H_{b}}
$$




$$
F_{\text {new }}^{\mathrm{m}}=\xi F_{\text {new }}
$$

Where, $L_{b}$ and $H_{b}$ are the length and width of the base wall panel, respectively; $L_{n}$ and $H_{n}$ are the length and width of the new wall panel, respectively. $F_{\text {new }}^{\mathrm{m}}$ is the modified failure load of the new wall panel; $F_{\text {new }}$ is the failure load predicted by the ST method. After introducing the size effect parameter $\xi$, the predicted failure load of the Wall Panel 1150 is $10.6 \mathrm{kN} / \mathrm{m}^{2}$ and the predicted error is only $0.52 \%$, which greatly improves the prediction accuracy of the ST method. Moreover, the average error of the ST method is slightly smaller than the GSED-based CA method.

Consequently, through the ST method, a base wall panel can be used to predict the failure loads of new wall panels with various plane sizes but same thickness.

To further validate the generality of the ST method, the case study is extended to the masonry wall panels tested by Lawrence [11]. These wall panels can follow the second constraint type. The wall panel, Test 8 (dimensions of $3 \mathrm{~m} \times 6 \mathrm{~m} \times 0.110 \mathrm{~m}$ ), is selected as the base wall panel. Table 3 lists the dimensions of the new wall panels, the tested failure loads, the predicted failure loads and the errors between the GSED-based CA method and the ST method. From Table 3, it can be seen that the accuracy of the ST method is $4.4 \%$ higher than the GSED-based CA method. This means that the ST method is adaptable for wall panels with various dimensions and boundary conditions, moreover, the materials used by Lawrence [11] to construct the wall panel are different from those of Chong [5].

\section{Discussion}

\subsection{Differences from the FEA method and GSED based CA method}

The ST method, as an innovative way to predict the failure loads of masonry wall panels, embodies its advantages in comparison with the traditional FEA method and the GSED-based CA method.

In a traditional FEA model, the material property parameters are obtained from the experimental tests, which could affect the accuracy of the FEA model. However, in the ST method, the FEA simulation is just used to calculate the SED values to represent the ST mode. The ST mode just uses the normalized SED values, where the material property parameters are eliminated, so that the material property parameters in the FEA model are not necessarily the actual values but are arbitrary assumed to enable the running of the simulation. Therefore, the predicted results by the ST method are stable and will not be affected by the material property parameters. On the other hand, the FEA methods are based on an assumed crack criterion to calculate the failure load, while in the ST method, the initial imperfection and variation in material and configuration of the wall panel have been considered and reflected in the test results of the base wall panel. Therefore, the predicted results of the new wall panel also include the initial defect and variation.

It seems that the proposed ST method is similar to the GSED-based CA method as both methods used the base wall panel to predict the failure load of new wall panels. However, the ST method has essential difference from the GSED-based CA method. The GSED-based CA method is an intelligent method and the GSED value of each cell on the new wall panel is projected from the base wall panel. Firstly, each cell on the new wall panel has a similar zone on the base wall panel and the CA method is applied to determine the similar zones on the two wall panels; and then the GSED values of each cell on the new wall panel is projected from the base wall panel according to the similar zone projecting criterion, i.e. the GSED of each cell on the new wall panel has the same value with the similar zone on the base wall panel. It is a mathematical mapping process. For more details on the GSED-based CA method, please refer to Huang et al. (2014). However, for the ST method, the SED of each cell on the new wall panel is extracted from the FEA results which is established according to the actual dimensions, boundary condition and the loading type of the new wall panel. Hence, the mechanism of the ST method is better than that of the GSEDbased CA method.

\subsection{Selection of the base wall panel}

Theoretically, any tested masonry wall panel can be taken as the base wall panel to predict the failure loads of new masonry walls panels with same boundary conditions and different in-plane sizes. To validate the universality of the base wall panel, the Wall Panel $1244(3.6 \mathrm{~m} \times 4.5 \mathrm{~m} \times 0.215 \mathrm{~m})$ is selected as the base wall panel to predict the failure loads of the masonry wall panels listed in Table 2 and the predicted results are listed in Table 5. Table 6 gives the comparison between two different base 
wall panels 1244 and 1173. Beware that the predicted load of the Wall Panel 1150 in Tables 5 and 6 are modified by Equations (10) and (11).

It can be seen from Table 6 that the predicted precision of both the Panel 1244 and Panel 1173 are within the range of engineering tolerance, and the accuracies of the results predicted based on two different base wall panels has a slighter difference of $3.52 \%$. Hence, the ST method has little dependence on the choice of the base wall panel. In other words, different base wall panels have little effect on the prediction accuracy. The difference of the results predicted by the ST method taking different base wall panels might be caused by the variability contained in the wall panels.

In a word, once the boundary condition, loading type and failure load of a wall panel are known, this wall panel could be used as the base wall panel to predict the failure load of the new wall panels with the same loading type and boundary conditions. Therefore, the ST method could be a user-friendly method.

Table 5. The parameters of the new wall panels and the predicted results by the ST method (Base Wall Panel 1244)

\begin{tabular}{|c|c|c|c|c|}
\hline \multirow{2}{*}{ No. } & \multirow{2}{*}{ Dimensions $(\mathrm{m})$} & \multicolumn{2}{|c|}{ Failure load $\left(\mathrm{kN} / \mathrm{m}^{2}\right)$} & \multirow{2}{*}{ Error } \\
\cline { 3 - 4 } & & Tested & ST method & $7.03 \%$ \\
\hline 1172 & $2.6 \times 2.7$ & 20.9 & 22.37 & $-1.26 \%$ \\
\hline 1169 & $2.6 \times 4.5$ & 9.5 & 9.38 & $13.4 \%$ \\
\hline 1150 & $2.6 \times 5.5$ & 10.7 & 12.13 & $-3.58 \%$ \\
\hline 1153 & $3.6 \times 5.5$ & 6.7 & 6.46 & $-7.08 \%$ \\
\hline 1237 & $4.5 \times 5.5$ & 6.5 & 6.04 & $6.47 \%$ \\
\hline \multicolumn{4}{|r}{} & Average error \\
\hline
\end{tabular}

Table 6. The failure loads predicted by the ST method and the errors

\begin{tabular}{|c|c|c|c|c|c|}
\hline \multirow{2}{*}{ No. } & \multirow{2}{*}{ Testing loads $\left(\mathrm{kN} / \mathrm{m}^{2}\right)$} & \multicolumn{2}{|c|}{ Failure loads $\left(\mathrm{kN} / \mathrm{m}^{2}\right)$} & \multicolumn{2}{c|}{ Errors } \\
\cline { 3 - 6 } & & $\begin{array}{c}\text { Base panel } \\
1244\end{array}$ & $\begin{array}{c}\text { Base panel } \\
1173\end{array}$ & Base panel 1244 & Base panel 1173 \\
\hline 1172 & 20.9 & 22.37 & 19.64 & $7.03 \%$ & $-6.03 \%$ \\
\hline 1169 & 9.5 & 9.38 & 8.54 & $-1.26 \%$ & $-10.11 \%$ \\
\hline 1150 & 10.7 & 10.6 & 12.13 & $13.4 \%$ & $0.5 \%$ \\
\hline 1153 & 6.7 & 6.46 & 5.67 & $-3.58 \%$ & $-15.37 \%$ \\
\hline 1237 & 6.5 & 6.04 & 5.30 & $-7.08 \%$ & $-18.46 \%$ \\
\hline \multicolumn{2}{|r}{ average error $E^{\text {ave }}$} & $6.47 \%$ & $10.09 \%$ \\
\hline
\end{tabular}

\section{Conclusions}

This paper proposes a ST method, including a summarized ST parameter and a size effect parameter, for predicting the failure loads of new masonry wall panels. The following conclusions can be drawn:

The relation between the ST mode parameter of laterally loaded masonry wall panel and its failure load, can be used to predict the failure load of a new wall panel with the same thickness based on the failure load of the tested base wall panel.

The accuracy of the ST method is higher than that of the yield line theory. When compared with the FEA method, the ST method also has better accuracy and simplicity in building up the FEA model. The results predicted by the ST method are stable and unaffected by the input parameters of material properties. Moreover, the accuracy of the ST method is slightly higher than the GSED-based CA method.

The ST method provides a new way in structural analysis, which could reflect the defects and variation of the new wall panels in their predicted results. What is more, the ST method use a unique parameter to represent the essential features in the structural configuration and behavior. 


\section{Acknowledgements}

The authors would like to thank for the financial sponsorship of Southwest Jiaotong University (10101X10096064), which provided the first fund to start this research subject. This project has been supported financially also by the Project of Young Scientists Fund (51508472), Science and Technology Innovation Project of the Fundamental Research Funds for the Central Universities (Grant No. 2682015CX004EM).

\section{References}

[1] Griffith, M. C., Lam, N. T., Wilson, J. L., Doherty, K.: Experimental investigation of unreinforced brick masonry walls in flexure, Structural Engineering, 130 (2004), 423-32.

[2] Donduren, M. S., Kanit, R., Kalkan, I., Gencel, O.: Influence of special plaster on the out-ofplane behavior of masonry walls, Earthquakes and Structures, 10 (2016), 4, 769-788.

[3] BSI (British Standards Institution): Code of practice for use of masonry, Structural use of unreinforced masonry, BS 5628 (1992), U. K.

[4] Baker, L. R.: Lateral loading of masonry panels: structural design of masonry, Cement and concrete association of Australia, (1980) Sydney, Australia.

[5] Chong, V. L.: The behavior of laterally loaded masonry panels with openings, Ph.D. thesis, (1993) Plymouth: University of Plymouth, U.K.

[6] Čanađija, M., Brčić, M., Brnić, J.: Bending behavior of single-layered grapheme nanosheets with vacancy defects, Engineering Review, 33 (2013), 1, 9-14.

[7] Noor-E-Khuda, S., Dhanasekar, M. Thambiratnam, D. P.: An explicit finite element modelling method for masonry walls under outof-plane loading, Engineering Structures, 113 (2016), 103-120.
[8] Monaco, A., Minafo, G., Cucchiara, C., Danna, J., Mendola, L.: Finite element analysis of the out-of-plane behavior of FRP strengthed masonry panels, Composites Part B: Enginering, 115 (2017), 188-202.

[9] Silva, L. C., Lourenco, P. B., Milani, G.: Nonlinear discrete homogenized model for masonry walls out-of-plane loaded, Journal of Structural Engineering, 143 (2017), 9.

[10] Brinker, R.: Yield line theory and material properties of lateral loaded masonry panels, Masonry Int., 1 (1984), 8-17.

[11] Lawrence, S. J.: Behaviour of brick masonry walls under lateral loading, Ph.D. thesis, (1983) Australia, University of South Wales.

[12] Zhou, G. C., Rafiq, M. Y., Bugmann, G., E.: Cellular automata model for predicting failure pattern of laterally loaded masonry wall panels, Journal of Computer in Civil Engineering, 20 (2006), 6, 400-409.

[13] Zhang, Y., Zhou, G. C., Xiong, Y., Rafiq, M. Y.: Techniques for predicting cracking pattern of masonry wallet using artificial neural networks and cellular automata, Journal of Computer in Civil Engineering, 24 (2010), 2, 161-172.

[14] Huang, Y. X., Zhang, Y., Wang, F. L., Zhou, G.C.: Mapping cracking pattern of masonry wall panel based on two-step criterion for matching zone similarity, Engineering Review, 34 (2014), 1, 39-45.

[15] Huang, Y. X., Zhang, Y., Zhang, M., Lv, C., Zhou, G. C.: Cellular automata method for mapping cracking patterns of laterally loaded wall panels with openings, Engnineering Review, 35 (2015), 1, 81-88

[16] Huang, Y. X., Zhang, Y., Zhang, M., Zhou, G. C.: Method for Predicting the Failure Load of Masonry Wall Panels Based on Generalized Strain Energy Density, Journal of Engineering Mechanics, 140 (2014), 8, 04014061(6). 